Johnson \& Wales University ScholarsArchive@JWU

Health \& Wellness Department Faculty

Publications and Research

College of Health \& Wellness

2016

\title{
Negative Experiences on Facebook and Depressive Symptoms among Young Adults
}

Samantha R. Rosenthal

Johnson \& Wales University - Providence, Samantha.Rosenthal@jwu.edu

Stephen L. Buka

Brown University School of Public Health

Brandon D.L. Marshall

Brown University School of Public Health

Kate B. Carey

Brown University School of Public Health

Melissa A. Clark

University of Massachusetts Medical School

Follow this and additional works at: https://scholarsarchive.jwu.edu/health_fac

Part of the Medicine and Health Sciences Commons

\section{Repository Citation}

Rosenthal, Samantha R.; Buka, Stephen L.; Marshall, Brandon D.L.; Carey, Kate B.; and Clark, Melissa A., "Negative Experiences on Facebook and Depressive Symptoms among Young Adults" (2016). Health \& Wellness Department Faculty Publications and Research. 11.

https://scholarsarchive.jwu.edu/health_fac/11

This Article is brought to you for free and open access by the College of Health \& Wellness at ScholarsArchive@JWU. It has been accepted for inclusion in Health \& Wellness Department Faculty Publications and Research by an authorized administrator of ScholarsArchive@JWU. For more information, please contact jcastel@jwu.edu. 
Original article

\title{
Negative Experiences on Facebook and Depressive Symptoms Among Young Adults
}

\author{
Samantha R. Rosenthal, Ph.D., M.P.H. ${ }^{a}{ }^{*}$, Stephen L. Buka, Sc.D. ${ }^{a}$, Brandon D. L. Marshall, Ph.D. ${ }^{a}$, \\ Kate B. Carey, Ph.D. ${ }^{\mathrm{b}}$, and Melissa A. Clark, Ph.D. ${ }^{\mathrm{c}}$

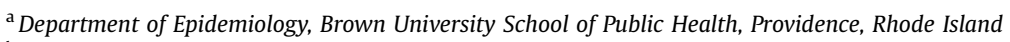 \\ ${ }^{\mathrm{b}}$ Department of Behavioral and Social Sciences, Brown University School of Public Health, Providence, Rhode Island \\ ${ }^{\mathrm{c}}$ Department of Quantitative Health Sciences and Center for Health Policy and Research, University of Massachusetts Medical School, Shrewsbury, Massachusetts
}

Article history: Received February 22, 2016; Accepted June 27, 2016

Keywords: Facebook; Social media; Depression; Transition to adulthood

\section{A B S T R A C T}

Purpose: To examine whether negative Facebook (FB) experiences were independently associated with depressive symptoms among young adults in a longitudinal family cohort.

Methods: Negative FB experiences were measured by type (e.g., bullying or meanness, unwanted contact, misunderstandings, or any), recency, number of experiences, and severity of upset. Depressive symptoms were assessed using the 10-item Center for Epidemiologic Studies Depression Scale. Generalized estimating equations were used to account for sibling correlation; adjusted models were constructed for each negative FB experience measure accounting for sex, race/ ethnicity, social support, adolescent depressive symptoms, parental psychological distress, average monthly income, educational attainment, and employment.

Results: In a sample of 264 young adults, all negative FB experience measures were significantly associated with depressive symptoms.

Conclusions: There is a clear association between negative FB experience and depressive symptoms. Future work should examine: (1) whether negative FB experiences cause incident depression or exacerbate preexisting depression; and (2) who is most prone to being upset by negative FB experiences. With further research, recommendations for limiting or altering FB use among high-risk subpopulations could be useful in reducing depressive symptoms.

(c) 2016 Society for Adolescent Health and Medicine. All rights reserved.

\section{IMPLICATIONS AND \\ CONTRIBUTION}

Negative Facebook experiences were associated with depressive symptoms. Experiences of bullying or meanness were uniquely linked to depressive symptoms; having as few as one to three negative lifetime experiences was associated with depressive symptoms. With further research, recommendations for altering Facebook use among highrisk subpopulations could be useful in reducing depressive symptoms.
In the past decade, Internet use has grown rapidly, particularly the use of social media (SM) such as Facebook (FB), which are virtual gathering places. FB has three times as many subscribers as there are U.S. citizens [1]. In a recent report, 95\% of adults aged 18-33 years reported use of the Internet, the highest

\footnotetext{
Conflicts of Interest: There were no study sponsors and the authors have no conflicts of interest to report.

* Address correspondence to: Samantha R. Rosenthal, Ph.D., M.P.H., Department of Epidemiology, Brown University, 121 S. Main St., Box G-S121-2, Providence, RI.

E-mail address: Samantha_Rosenthal@brown.edu (S.R. Rosenthal).
}

proportion among any age group, $83 \%$ of whom reported SM use [1]. Research on SM use has focused on adolescents and college students; to our knowledge, there have been no studies among young adults older than college age. Yet the transition from adolescence to early adulthood is a vulnerable developmental stage in which an individual's support system (including online social supports) can influence psychopathology and risk behaviors [2-5].

The increasing use of SM, particularly during vulnerable developmental stages, has triggered interest in how its use is related to psychological and emotional states. SM can likely have 
both positive and negative effects on mental health. For example, researchers found that online social connectedness may act as an additional social medium from which a range of positive psychological outcomes can be derived [6]. However, another study found that, although FB can help college students obtain online social support, there was little effect on well-being [7]. A study conducted by FB employees found that emotions expressed by others on $\mathrm{FB}$ - whether positive or negative-can influence an individual's own emotions [8]. For the purposes of this research, we will be focusing specifically on negative Facebook experiences (NFEs).

Media outlets and researchers have suggested that experiences on FB may increase the risk of depression, referred to as "Facebook depression" which some believe to be triggered by spending a great deal of time using SM. In particular, there is concern that addictive SM use, cyberbullying, and the evocation of jealousy due to the constant exposure to others' personal information may lead to depression [4,9-11]. Chen and Lee [9] found evidence that both communication overload and reduced self-esteem are mechanisms by which FB interaction can influence psychological distress. Yet, Jelenchick et al. [11] found no relationship between frequency of social networking site use and depression in a college sample. Despite mixed results and media attention, there is limited research examining the relationship between SM use and mental health.

It has been suggested that negative experiences online are a common source of risk for young people. For example, in a national cross-sectional online survey of 1,588 young people ages 10-17, 33\% reported online harassment in the last year; $9 \%$ reported an incident on an SM site specifically [12]. Prior research has also demonstrated the negative effects of bullying on well-being, including depression; however, limited research has been conducted on the specific nature and effects of negative SM experiences [13-15].

All studies of SM use to date have focused on characteristics of use such as comments in postings, behaviors posted in pictures, and frequency of overall use. In this study (and to our knowledge for the first time), we examined the subjective effect of SM experiences; specifically, how negative interactions with others on SM may be related to depression. Measuring the occurrence of negative interactions (rather than frequency of use or general interactions more broadly) on SM is more relevant to our theorythat negative SM experiences can lead to or exacerbate depressive symptoms. Current gaps in knowledge suggest that information is needed to confirm or refute whether a relationship exists between SM experience and depressive symptoms. We studied a cohort previously assessed during adolescence (mean age of 14), before the advent of SM, and then again when the cohort was 21-30 years old. Thus, we had a unique opportunity to use a longitudinal cohort to determine whether negative SM experiences were independently associated with depressive symptoms among young adults, accounting for adolescent depressive symptoms and parental psychological distress occurring prior to SM use.

\section{Methods}

\section{Participants and sample}

The New England Family Study (NEFS) third-generation cohort represents the third generation of participants in the NEFS, an intergenerational cohort established to follow-up the adult offspring born to women enrolled during pregnancy as part of the U.S. Collaborative Perinatal Project from 1959 to 1966 [16]. During the Collaborative Perinatal Project, women were studied extensively during pregnancy (G1), and their offspring's (G2) development was studied through age 7 years. The NEFS was established between 2001 and 2004 to recruit a subset of the second-generation adult cohort to investigate the intergenerational transmission of tobacco use and nicotine dependence; of this group 1,674 were enrolled (74\%). Information was elicited from the G2s by interviewer-administered and self-administered instruments [17]. In many cases, the G2 spouse or coparent was unavailable for interview in which case the primary G2 provided proxy information for the spouse for key psychopathology measures. More details on sampling and recruitment have been described previously [17]. This phase also entailed enrolling a sample of the third-generation adolescent, biological offspring of Collaborative Perinatal Project participants who were age eligible (e.g., between 12 and 17 years), including siblings, who had parental consent, and were living within 100 miles of study sites in Providence or Boston $(n=564)$; a baseline interview was conducted at mean age of 14 years.

\section{Design and data collection}

In 2013-2014, follow-up data collection was initiated with the third-generation cohort members who completed the adolescent baseline interview. All prior third-generation cohort members who consented to be contacted for future studies at the baseline assessment were eligible for recruitment $(n=564)$. Participants were located via contact information collected previously, as well as FB and other frequently used location services. Participants were then contacted to participate in a study about SM use. A brief explanation of study participation was given, and verbal and web-based consent were elicited for participation in a 15- to 20-minute web-based survey. Web-based data collection was performed using Illume, a product of DatStat, Inc. (Seattle, WA). Participants were compensated $\$ 25$ electronic gift certificate for their participation in this study. Among those successfully contacted ( $n=334,59 \%$ ), there was an $80 \%$ response rate $(n=266)$. This yielded an overall response rate of $47 \%$. All those who reported ever using FB were eligible for inclusion in the analytic sample $(n=264)$. Given the overall response rate, the eligible sample was significantly more female and white, nonHispanic than the total third-generation cohort $(n=564)$, yet not significantly different by adolescent depressive symptoms, parental household income, parental education, or parental psychological distress. The final analytic sample included 197 families with 53 sibling pairs and seven sibling triplets. Despite this relatively small sample size, we have used a cohort to leverage the opportunity to account for parental psychological distress and prior adolescent depressive symptoms. This study protocol was approved by the university institutional review board.

\section{Measures}

Primary outcome. Depressive symptoms, as measured by the Center for Epidemiologic Studies Short Depression Scale (CES-D 10 ), were the primary outcome. The CES-D is a screening tool commonly used to identify depressive symptoms among the general population. The scale's validity and reliability to detect clinical and nonclinical depressive symptoms have been 
Table 1

Definitions of measures of negative experiences on Facebook

\begin{tabular}{|c|c|}
\hline & Definition \\
\hline \multicolumn{2}{|l|}{ Lifetime experience } \\
\hline Bullying or meanness (1) & $\begin{array}{l}\text { Responded "yes" to "Throughout your use of Facebook, have you ever encountered bullying or meanness?"; "no" } \\
\text { and "do not know" response categorized as no lifetime experience }\end{array}$ \\
\hline Unwanted contact (2) & $\begin{array}{l}\text { Responded "yes" to "Throughout your use of Facebook, have you ever encountered unwanted contact?"; "no" } \\
\text { and "do not know" response categorized as no lifetime experience }\end{array}$ \\
\hline Misunderstandings (3) & $\begin{array}{l}\text { Responded "yes" to "Throughout your use of Facebook, have you ever encountered misunderstandings?"; "no" } \\
\text { and "do not know" response categorized as no lifetime experience }\end{array}$ \\
\hline Any negative experience (4) & Categorized as having lifetime experience for any of $(1-3)$; else no lifetime experience \\
\hline \multicolumn{2}{|l|}{ Past-year experience } \\
\hline Bullying or meanness (1A) & $\begin{array}{l}\text { Categorized as having lifetime experience (1) and response to "How old were you when an experience of } \\
\text { bullying or meanness on Facebook occurred most recently?" was within } 1 \text { year of reported current age; } \\
\text { else no past-year experience }\end{array}$ \\
\hline Unwanted contact $(2 \mathrm{~A})$ & $\begin{array}{l}\text { Categorized as having lifetime experience (2) and response to "How old were you when an experience of } \\
\text { unwanted contact on Facebook occurred most recently?" was within } 1 \text { year of reported current age; else } \\
\text { no past-year experience }\end{array}$ \\
\hline Misunderstandings (3A) & $\begin{array}{l}\text { Categorized as having lifetime experience (3) and response to "How old were you when misunderstandings } \\
\text { on Facebook occurred most recently?" was within } 1 \text { year of reported current age; else no past-year experience }\end{array}$ \\
\hline Any negative experience (4A) & Categorized as having past-year experience for any of $(1 \mathrm{~A}-3 \mathrm{~A})$; else no past-year experience \\
\hline \multicolumn{2}{|l|}{ Number of lifetime experiences } \\
\hline Bullying or meanness (1B) & $\begin{array}{l}\text { None: categorized as no lifetime experience (1); one to three: categorized as having lifetime experience (1); } \\
\text { response to "How many times has this occurred?" was one, two, or three; and four or more: categorized as } \\
\text { having lifetime experience (1) and response to "How many times has this occurred?" was four or more }\end{array}$ \\
\hline Unwanted contact (2B) & $\begin{array}{l}\text { None: categorized as no lifetime experience (2); one to three: categorized as having lifetime experience (2); } \\
\text { response to "How many times has this occurred?" was one, two, or three; and four or more: categorized as } \\
\text { having lifetime experience (2) and response to "How many times has this occurred?" was four or more }\end{array}$ \\
\hline Misunderstandings (3B) & $\begin{array}{l}\text { None: categorized as no lifetime experience (3); one to three: categorized as having lifetime experience (3); } \\
\text { response to "How many times has this occurred?" was one, two, or three; and four or more: categorized as } \\
\text { having lifetime experience (3) and response to "How many times has this occurred?" was four or more }\end{array}$ \\
\hline Any negative experience (4B) & $\begin{array}{l}\text { None: categorized as no lifetime experience for all }(1-3) \text {; one to three: categorized as having lifetime experience } \\
\text { for any }(1-3) \text { and cumulative number of experiences }(1-3) \text { was one, two, or three; and four or more: } \\
\text { categorized as having lifetime experience for any }(1-3) \text { and cumulative number of experiences }(1-3) \\
\text { was four or more }\end{array}$ \\
\hline \multicolumn{2}{|c|}{ Severity of upset for most recent experience } \\
\hline Bullying or meanness $(1 \mathrm{C})$ & $\begin{array}{l}0 \text { if categorized as no lifetime experience (1); if categorized as having lifetime experience (1), } 1-10 \text { based on } \\
\text { response to "How upsetting was this most recent experience of bullying or meanness on Facebook to you } \\
\text { on a scale of } 1 \text { through } 10 \text { where } 1 \text { is "not at all upsetting" and } 10 \text { is "extremely upsetting" }\end{array}$ \\
\hline Unwanted contact (2C) & $\begin{array}{l}0 \text { if categorized as no lifetime experience (2); if categorized as having lifetime experience (1), } 1-10 \text { based on } \\
\text { response to "How upsetting was this most recent experience of bullying or meanness on Facebook to you on a } \\
\text { scale of } 1 \text { through } 10 \text { where } 1 \text { is "not at all upsetting" and } 10 \text { is "extremely upsetting" }\end{array}$ \\
\hline Misunderstandings ( $3 \mathrm{C}$ ) & $\begin{array}{l}0 \text { if categorized as no lifetime experience (3); if categorized as having lifetime experience (4), } 1-10 \text { based on } \\
\text { response to "How upsetting was this most recent experience of bullying or meanness on Facebook to you on a } \\
\text { scale of } 1 \text { through } 10 \text { where } 1 \text { is "not at all upsetting" and } 10 \text { is "extremely upsetting" }\end{array}$ \\
\hline All negative experiences (4C) & $\begin{array}{l}0 \text { if categorized as no lifetime experience for all of } 1-3 \text {; if categorized as having lifetime experience for any of } \\
1-3 \text {, average severity of upset for } 1 \mathrm{C}-3 \mathrm{C}\end{array}$ \\
\hline \multicolumn{2}{|c|}{ Severity of upset for most recent past-year experience } \\
\hline Bullying or meanness (1D) & Same value as $1 \mathrm{C}$ if categorized as having past-year experience $(1 \mathrm{~A})$; else 0 \\
\hline Unwanted contact (2D) & Same value as $2 \mathrm{C}$ if categorized as having past-year experience (2A); else 0 \\
\hline Misunderstandings (3D) & Same value as $3 \mathrm{C}$ if categorized as having past-year experience ( $3 \mathrm{~A})$; else 0 \\
\hline Any negative experience (4D) & $\begin{array}{l}0 \text { if categorized as no past-year experience for all of } 1 \mathrm{~A}-3 \mathrm{~A} \text {; if categorized as having past-year experience for } \\
\text { any of } 1 \mathrm{~A}-3 \mathrm{~A} \text {, average severity of upset for those past year }(1 \mathrm{C}-3 \mathrm{C})\end{array}$ \\
\hline
\end{tabular}

previously established [18]. The CES-D 10 consists of 10 items. Participants with a score of 10 or more were considered to have depressive symptoms [19].

Primary exposures. Participants were first asked, "Have you ever used Facebook?" All those responding "yes" were eligible to answer questions about negative SM experiences. Negative SM experiences were based on two gender-specific focus groups and an article by Christofides et al. [5]. In 2011, we conducted two gender-specific focus groups, recruiting via Craigslist and posting flyers; participants were in the same age group (21-30 years) as those in this study population. The focus group discussions elicited descriptions of both negative and positive SM experiences. Results from thematic analyses of the focus groups as well as findings from other qualitative research were used to identify different types of NFEs: (1) bullying or meanness; (2) unwanted contact; and (3) misunderstandings [5].

Negative SM experiences were measured in several ways. For each type of experience (e.g., bullying or meanness, unwanted contact, misunderstandings, or any negative experience), participants were asked about lifetime experience, past-year experience, number of lifetime experiences (none, $1-3$, or 4 or more), severity of upset from most recent experience (continuous: from 0 to 10 ; also averaged across types), and severity of upset of most recent past-year experience (continuous: from 0 to 10; also averaged across types). The detailed definition for these negative experiences is in Table 1 . All of these measures were found to have good test-retest reliability in a follow-up 2-6 weeks later. 
Other covariates. Sex was categorized as male or female. Age was asked at the time of the survey and considered as a continuous variable. Race/ethnicity was categorized as white, non-Hispanic versus all others. Participants were considered to have social support if they responded "always" or "usually" to the question, "How often do you get the social and emotional support you need?" Daily FB use was determined by responses to the question, "When using Facebook over the past year, how frequently did you use Facebook?" Those participants who responded "multiple times per day" or "daily" were categorized as daily FB users. All those who responded "a few times per week," "weekly," "less than weekly," or "not at all" were categorized as not being daily FB users. Average monthly income was categorized as: $<\$ 500, \$ 500-\$ 1,499, \$ 1,500-\$ 2,499, \$ 2,500$ or more, and do not know. Educational attainment was categorized as having a high school/GED or less versus having more than a high school education. Participants were categorized as employed if they indicated full-time or part-time employment.

Depressive symptoms in the adolescent baseline assessment were measured by a module from the National Comorbidity Survey Adolescent Supplement, an adapted version of the World Health Organization's Composite International Diagnostic Interview [20]. Specifically, adolescent depressive symptoms were characterized by a "yes" response to the question, "Over the past year have you ever had periods that lasted several days or longer when you felt sad or depressed?" All those who responded "yes" were categorized as having adolescent depressive symptoms.

Self-reported parental psychological distress at baseline was assessed using the Diagnostic and Statistical Manual of Mental Disorders, 4th Edition criteria for at least one major depressive episode. When available, self-reports were used for both biological parents. In many cases, however, this information was not available. In these instances, spousal responses to the following question were used: "Was (name) ever treated for a psychological or emotional problem? This could include staying overnight in a hospital or treatment facility, taking medicine, or seeing a psychiatrist, psychologist, social worker, doctor, or other health professional." An affirmative response was used to identify a history of psychological distress for the parent reported on. Based on responses to these questions, parental psychological distress was categorized as "none" when both parents had no history of psychological distress, "some" when at least one parent had a history of psychological distress, or "unknown" when both parents had missing information or when one parent had no history of major depressive episode while the other's status was missing.

\section{Statistical analysis}

All analyses controlled for the nonindependence of siblings enrolled into the study using generalized estimating equations. First, we examined the social and demographic characteristics by depressive symptoms in bivariate analyses. Next, we calculated crude and adjusted odds ratios of depressive symptoms for all NFE measures. Adjusted models were constructed for each exposure of interest accounting for sex, race/ethnicity, social support, adolescent depressive symptoms, parental psychological distress, average monthly income, educational attainment, and employment-all measures previously found to be associated with depression-as well as daily FB use, which was previously linked to an increase in negative online experiences [21-25]. All models were specified with the binomial
Table 2

Social and demographic characteristics of young adults aged 21-30 years in the third-generation New England Family Study by depressive symptomatology

\begin{tabular}{lrlr}
\hline & $\mathrm{N}=264(\%)$ & \multicolumn{2}{c}{ Depressive symptoms } \\
\cline { 3 - 4 } & & $\mathrm{N}=63(24 \%)$ & $p$ value \\
\hline Female & $157(59)$ & $36(57)$ & .677 \\
White, non-Hispanic & $237(90)$ & $53(85)$ & .176 \\
Social support & $204(77)$ & $30(48)$ & $<.001$ \\
Adolescent depressive symptoms & $91(35)$ & $32(51)$ & $\mathbf{. 0 0 2}$ \\
Daily Facebook use & $201(76)$ & $48(76)$ & .935 \\
Parent psychological distress & & & $\mathbf{0 3 0}$ \\
$\quad$ None & $125(47)$ & $21(33)$ & \\
Some & $83(32)$ & $25(40)$ & \\
$\quad$ Unknown & $56(21)$ & $17(27)$ & $\mathbf{. 0 0 2}$ \\
Average monthly income & & & \\
$\quad$ \$500 & $31(12)$ & $13(21)$ & \\
$\quad$ \$500-\$1,499 & $71(27)$ & $20(32)$ & \\
\$1,500-\$2,499 & $69(26)$ & $14(22)$ & \\
$\quad$ \$2,500 or more & $81(31)$ & $10(16)$ & \\
$\quad$ Do not know & $12(4)$ & $6(9)$ & \\
More than high school education & $157(59)$ & $26(41)$ & $\mathbf{. 0 0 1}$ \\
Employed & $214(81)$ & $41(65)$ & $<.001$ \\
\hline
\end{tabular}

$p$ values were generated using generalized estimating equations to account for sibling correlation using the binomial family, a logit link function, and an exchangeable correlation structure. All bold $p$ values indicate significance at an $\alpha=.05$ threshold. Depressive symptomatology was assessed by the Center for Epidemiologic Studies Short Depression Scale (CES-D 10) using a cutoff score of $\geq 10$.

distribution, a logit link function, and an exchangeable correlation structure. All statistical analyses were conducted using Stata, version 12 [26].

\section{Results}

More than half of the sample was female (59\%) and white, non-Hispanic (90\%) (Table 2). Most participants reported having a lifetime negative experience (82\%), having a past-year negative experience (55\%), and having four or more lifetime NFEs (63\%). Unwanted contact and misunderstandings were the most common lifetime NFEs (61\% each). Yet, the most recent experience of bullying or meanness was the most upsetting (among those having the experience, mean $=4.57$, standard deviation $=.25$; Table 3).

Among the full analytic sample, CES-D scores ranged from 0 to 30 with a mean of 6.56 (standard deviation $=.33$ ). Sixtythree participants (24\%) were categorized as having depressive symptoms based on their CES-D scores. Young adults with social support, who were employed, who had more than a high school education, and higher average monthly income were significantly less likely to have depressive symptoms. Those with a history of parental psychological distress or adolescent depressive symptoms were more likely to have depressive symptoms in young adulthood (Table 2).

\section{Lifetime negative FB experiences}

Examination of crude relationships between NFEs and current depressive symptoms showed that those who reported lifetime NFEs of any type (e.g., bullying or meanness, unwanted contact, misunderstandings, or any negative experience) had greater odds of depressive symptoms (Table 3 ). These significant relationships remained in fully adjusted models. 
Table 3

Odds of depressive symptoms associated with different types of negative Facebook experiences using generalized estimating equations to account for sibling relationship among young adults aged $21-30$ years

\begin{tabular}{|c|c|c|c|}
\hline & \multirow[t]{2}{*}{$N=264(\%)$} & \multicolumn{2}{|c|}{ Depressive symptoms } \\
\hline & & Crude (95\% CI) & Adjusted $(95 \% \mathrm{CI})^{\mathrm{a}}$ \\
\hline \multicolumn{4}{|l|}{ Lifetime experience } \\
\hline Bullying or meanness & $115(44)$ & $2.75(1.53,4.91)$ & $3.45(1.73,6.88)$ \\
\hline Unwanted contact & $161(61)$ & $2.08(1.12,3.88)$ & $2.51(1.20,5.28)$ \\
\hline Misunderstandings & $161(61)$ & $2.25(1.19,4.24)$ & $2.83(1.31,6.09)$ \\
\hline Any negative experience & $217(82)$ & $2.54(1.01,6.39)$ & $3.21(1.11,9.31)$ \\
\hline \multicolumn{4}{|l|}{ Past-year experience } \\
\hline Bullying or meanness & $44(18)$ & $1.40(.67,2.93)$ & $1.53(.63,3.69)$ \\
\hline Unwanted contact & $94(37)$ & $1.86(1.04,3.35)$ & $1.98(.98,3.98)$ \\
\hline Misunderstandings & $95(38)$ & $2.12(1.19,3.80)$ & $2.60(1.28,5.30)$ \\
\hline Any negative experience & $143(55)$ & $2.21(1.19,4.09)$ & $2.33(1.12,4.85)$ \\
\hline \multicolumn{4}{|c|}{ Number of lifetime experiences } \\
\hline \multicolumn{4}{|l|}{ Bullying or meanness } \\
\hline None & $149(58)$ & 1.00 (ref) & 1.00 (ref) \\
\hline One to three & $47(18)$ & $3.06(1.47,6.37)$ & $4.06(1.73,9.52)$ \\
\hline Four or more & $59(23)$ & $2.54(1.27,5.10)$ & $2.89(1.22,6.87)$ \\
\hline \multicolumn{4}{|l|}{ Unwanted contact } \\
\hline None & $103(41)$ & 1.00 (ref) & 1.00 (ref) \\
\hline One to three & $70(28)$ & $1.63(.77,3.48)$ & $1.50(.59,3.79)$ \\
\hline Four or more & $81(32)$ & $2.46(1.23,4.91)$ & $3.06(1.36,6.89)$ \\
\hline \multicolumn{4}{|l|}{ Misunderstandings } \\
\hline None & $103(41)$ & 1.00 (ref) & 1.00 (ref) \\
\hline One to three & 49 (19) & $2.13(.94,4.83)$ & $2.59(.94,7.10)$ \\
\hline Four or more & $101(40)$ & $2.33(1.18,4.62)$ & $2.94(1.29,6.72)$ \\
\hline \multicolumn{4}{|l|}{ Any negative experience } \\
\hline None & 47 (19) & 1.00 (ref) & 1.00 (ref) \\
\hline One to three & $44(18)$ & $1.12(.33,3.83)$ & $1.22(.27,5.42)$ \\
\hline \multirow[t]{2}{*}{ Four or more } & $158(63)$ & $3.15(1.24,8.05)$ & $3.87(1.31,11.45)$ \\
\hline & \multicolumn{3}{|c|}{$\begin{array}{l}\text { Mean (SD) among those } \\
\text { having experience }\end{array}$} \\
\hline \multicolumn{4}{|c|}{ Severity of upset for most recent experience } \\
\hline Bullying or meanness & $4.57(.25)$ & $1.21(1.10,1.33)$ & $1.25(1.11,1.41)$ \\
\hline Unwanted contact & $3.61(.21)$ & $1.23(1.11,1.37)$ & $1.19(1.05,1.34)$ \\
\hline Misunderstandings & $4.19(.20)$ & $1.14(1.03,1.26)$ & $1.16(1.03,1.32)$ \\
\hline All negative experiences & $2.74(.15)$ & $1.34(1.17,1.53)$ & $1.36(1.15,1.61)$ \\
\hline \multicolumn{4}{|c|}{ Severity of upset for most recent past-year experience } \\
\hline Bullying or meanness & $4.55(.43)$ & $1.09(.97,1.23)$ & $1.09(.95,1.25)$ \\
\hline Unwanted contact & $3.48(.29)$ & $1.22(1.10,1.37)$ & $1.17(1.03,1.34)$ \\
\hline Misunderstandings & $4.13(.26)$ & $1.14(1.03,1.27)$ & $1.13(1.00,1.28)$ \\
\hline Any negative experience & $2.23(.16)$ & $1.29(1.11,1.50)$ & $1.26(1.04,1.51)$ \\
\hline
\end{tabular}

All models use generalized estimating equations to account for sibling correlation with the binomial distribution and logit link function. Bold results indicate statistical significance with $p<0.05$.

a Adjusted for sex, race/ethnicity, social support, adolescent depressive symptoms, daily Facebook use, parental psychological distress, average monthly income, educational attainment, and employment.

\section{Past-year negative FB experiences}

Past-year NFEs were also associated with current depressive symptoms; this was true for all negative experience types except for bullying or meanness (Table 3). In the fully adjusted models, significant positive relationships between past-year misunderstandings and depressive symptoms as well as any pastyear negative FB experience and depressive symptoms remained.

\section{Number of lifetime negative FB experiences}

For each NFE type, having four or more experiences was associated with having depressive symptoms compared to having none. For bullying or meanness only, those reporting one to three experiences had 3.06 95\% confidence interval $(1.47,6.37)$ times the odds of depressive symptoms compared to those reporting none (Table 3 ). In adjusted models these significant relationships remained.

\section{Severity of upset for most recent negative FB experiences}

With each unit increase in reports of upset for most recent experiences of bullying or meanness, unwanted contact, or misunderstandings, participants had significantly greater odds of depressive symptoms. Similarly, with each unit increase in average reports of upset for all types of negative experience, participants were significantly more likely to have depressive symptoms. All significant associations remained in the fully adjusted models (Table 3 ).

\section{Severity of upset for most recent past-year negative FB experiences}

Finally, when considering severity of upset for only past-year experiences, with each unit increase in reports of upset for experiences of unwanted contact, misunderstandings, or the average for all negative experience types, participants were significantly more likely to have depressive symptoms. 
In adjusted models, these significant relationships remained (Table 3).

\section{Discussion}

This study aimed to examine the relationship between negative experiences on FB and depressive symptoms. Findings suggest the lifetime, past-year, lifetime number, and severity of upset of most recent and most recent past-year negative FB experiences were all associated with depressive symptoms. Similar to other nationally representative young adult samples, $24 \%$ of participants in this study were categorized as having selfreported depressive symptoms based on their CES-D scores [27]. Also, similar to previous literature, low social support, adolescent depressive symptoms, parental psychological distress, lower income, less education, and being unemployed were all associated with self-reported depressive symptoms [22-24].

\section{Lifetime negative FB experiences}

We assessed whether having lifetime negative FB experiences was associated with depressive symptoms. Lifetime experience could have occurred as early as 2004, when FB was created. It was important to assess lifetime experience because a traumatic experience on FB in adolescence or young adulthood could potentially have long-term effects on depressive symptoms, or may be reflective of long-term depression risk. For lifetime experiences, reports of all NFE types were strongly associated with depressive symptoms.

Young people who are depressed and have low self-worth are more likely to be bullied, while other research suggests that being involved in bullying causes subsequent depression [28-30]. The same may be true for online bullying and unwanted contact.

Misunderstandings on FB may be indicative of stressful life events; this is supported by Christofides et al. [5] qualitative research, in which study participants' reported examples of misunderstandings on FB as "when information posted online lead to issues with friends or a boss." Stressors and stressful life events, particularly in young adulthood, have been repeatedly linked to depression [31-33].

\section{Past-year negative FB experiences}

In contrast to all lifetime NFEs, assessing only past-year negative experiences helped us to understand whether a recent NFE was more strongly associated with depressive symptoms. However, evidence from the findings suggest that past-year NFE was not more strongly associated with depressive symptoms than having a lifetime experience, specifically for bullying or meanness and unwanted contact. This suggests that having an NFE in adulthood, specifically bullying or meanness or unwanted contact, may be less distressing than in adolescence.

\section{Number of lifetime negative FB experiences}

We also assessed the association between the number of lifetime NFEs a person had and depressive symptoms, attempting to detect any threshold effect that might exist. Having four or more experiences of any type of negative FB experience were all associated with depressive symptoms. Each of these negative experiences is likely to cause some form of social stress. Having frequent experiences of this sort may cause a young person to have chronic stress. Similar to the effects of a stressor or stressful life event, chronic stress is known to be associated with depression $[34,35]$.

Importantly, for experiences of bullying or meanness on FB, having one to three experiences was also associated with depressive symptoms. This implies that experiences of bullying or meanness on FB are unique; having even a single experience of bullying or meanness on FB was associated with depressive symptoms, while individuals needed to have at least four experiences of other types to exhibit the same association with depressive symptomatology.

\section{Severity of upset for most recent negative FB experiences}

It was important to assess the severity of upset resulting from a person's most recent NFE because, for certain NFE types, how upsetting the experience was, rather than just having the experience, may be driving its association with depressive symptoms. The more upsetting a person's most recent NFE was rated, the more likely they were to also self-report depressive symptoms. The severity of upset reported from these experiences may be correlated with the amount of life stress resulting from that particular experience; the more stressful the experience, the more likely a person is to be depressed [31-33]. This variation in upset that we observed could be due to the particular context or nature of the online experience or to how prone a person is to being upset by online negative experiences, such as one's fear of negative evaluation.

\section{Severity of upset for most recent negative FB experiences}

In contrast to upset from most recent NFEs, assessing upset from most recent past-year NFEs helped us to understand whether upset from a recent NFE was more strongly associated with depressive symptoms. However, upset from most recent past-year NFEs was not more strongly associated with depressive symptoms than upset from most recent lifetime NFE, specifically for bullying or meanness. Therefore, upset from an NFE in young adulthood, specifically bullying or meanness, may be less distressing than upset from bullying or meanness on FB in adolescence.

\section{Limitations}

There are several limitations of this study. First, we do not know if reported negative experiences preceded the onset of depressive symptoms. Therefore, having depressive symptoms could increase one's risk for NFEs or cause one to be more upset by an NFE. Fortunately, we were able to control for preexisting depressive symptoms in adolescence prior to any NFE. Second, measures of NFE may be prone to recall bias. For example, participants may not remember NFEs from as early as 2004 when FB first started. Those who had more salient or more upsetting experiences may be more likely to remember the experiences, leading to differential misclassification of the exposure and potentially overestimating the association with depressive symptoms. Mitigating this concern, the reports of NFEs were found to be reliable in test-retest analysis. Third, questions regarding NFEs were consistently asked prior to the CES-D 10 assessment for all participants. Potentially, answering questions about NFEs could introduce a priming effect for reporting more 
depressive symptoms in the CES-D 10 assessment. Finally, the sample is predominantly white, non-Hispanic and majority female-and even significantly more so than the full thirdgeneration cohort. Thus, these findings may not be generalizable to all young adults who have used FB.

In conclusion, lifetime negative FB experience, past-year negative $\mathrm{FB}$ experience, number of lifetime negative FB experiences, and severity of upset from most recent and most recent past-year negative experiences were all associated with depressive symptoms. Experiences of bullying or meanness on FB were uniquely linked to depressive symptoms; having as few as one to three negative lifetime experiences was associated with depressive symptoms. Future work should examine: (1) whether negative FB experiences cause incident depression or exacerbate preexisting depression; and (2) who is most prone to being upset by negative FB experiences. With further research, recommendations for limiting or altering FB use among high-risk subpopulations could be useful in reducing depressive symptoms.

\section{References}

[1] Zickuhr K. Generations 2010. Pew Internet \& American Life Project; Washington, DC: Pew Research Center; 2010. Available at: http://pewinternet. org/Reports/2010/Generations-2010.aspx. Accessed April 24, 2014.

[2] Schulenberg JE, Sameroff AJ, Cicchetti D. The transition to adulthood as a critical juncture in the course of psychopathology and mental health. Dev Psychopathol 2004;16:799-806.

[3] Staff J, Schulenberg JE, Maslowsky J, et al. Substance use changes and social role transitions: Proximal developmental effects on ongoing trajectories from late adolescence through early adulthood. Dev Psychopathol 2010;22: 917-32.

[4] O'Keeffe GS, Clarke-Pearson K, Council on Communications and Media. The impact of social media on children, adolescents, and families. Pediatrics 2011;127:800-4.

[5] Christofides E, Muise A, Desmarais S. Risky disclosures on Facebook: The effect of having a bad experience on online behavior. J Adolesc Res 2012; 27:714-31.

[6] Grieve R, Indian M, Witteveen K, et al. Face-to-face or Facebook: Can social connectedness be derived online? Comput Human Behav 2013;29:604-9.

[7] Liu CY, Yu CP. Can Facebook use induce well-being? Cyberpsychol Behav Soc Netw 2013;16:674-8.

[8] Kramer AD, Guillory JE, Hancock JT. Experimental evidence of massive-scale emotional contagion through social networks. PNAS 2014:111:8788-90.

[9] Chen W, Lee KH. Sharing, liking, commenting, and distressed? The pathway between Facebook interaction and psychological distress. Cyberpsychol Behav Soc Netw 2013;16:728-34.

[10] Christofides E, Muise A, Desmarais S. Information disclosure and control on Facebook: Are they two sides of the same coin or two different processes? CyberPsychol Behav 2009;12:341-5.

[11] Jelenchick LA, Eickhoff JC, Moreno MA. "Facebook depression?" Social networking site use and depression in older adolescents. J Adolesc Health 2013;52:128-30.
[12] Mitchell KJ, Ybarra M, Finkelhor D. The relative importance of online victimization in understanding depression, delinquency, and substance use. Child Maltreat 2007;12:314-24.

[13] Gini G, Pozzoli T. Association between bullying and psychosomatic problems: A meta-analysis. Pediatrics 2009;123:1059-65.

[14] Hawker DS, Boulton MJ. Twenty years' research on peer victimization and psychosocial maladjustment: A meta-analytic review of cross-sectional studies. J Child Psychol Psychiatry 2000;41:441-55.

[15] Williams KR, Guerra NG. Prevalence and predictors of internet bullying. J Adolesc Health 2007;41(6 Suppl 1):S14-21.

[16] Buka SL, Lipsitt LP, Tsuang MT. Birth complications and psychological deviancy: A 25-year prospective inquiry. Acta Paediatr Jpn 1988;30: 537-46.

[17] Clark MA, Rogers ML, Boergers J, et al. A transdisciplinary approach to protocol development for tobacco control research: A case study. Transl Behav Med 2012;2:431-40.

[18] Radloff LS. The CES-D scale: A self report depression scale for research in the general. Appl Psychol Meas 1977;1:385-401.

[19] Bradley KL, Bagnell AL, Brannen CL. Factorial validity of the center for epidemiological studies depression 10 in adolescents. Issues Ment Health Nurs 2010;31:408-12.

[20] Kessler RC, Avenevoli S, Costello EJ, et al. National comorbidity survey replication adolescent supplement (NCS-A): II. Overview and design. J Am Acad Child Adolesc Psychiatry 2009;48:380-5.

[21] Plant EA, Sachs-Ericsson NS. Racial and ethnic differences in depression: The roles of social support and meeting basic needs. J Consult Clin Psychol 2004;72:41-52.

[22] Cohen S, Wills TA. Stress, social support, and the buffering hypothesis. Psychol Bull 1985;98:310-57.

[23] Lorant V, Deliege D, Eaton $W$, et al. Socioeconomic inequalities in depression: A meta-analysis. Am J Epidemiol 2003;157:98-112.

[24] Miech RA, Shanahan MJ. Socioeconomic status and depression over the life course. J Health Soc Behav 2000;41:162-76.

[25] Hinduja S, Patchin JW. Cyberbullying: An exploratory analysis of factors related to offending and victimization. Deviant Behav 2008;29:129-56.

[26] StataCorp. Stata statistical software: Release 10. College Station, TX: StataCorp LP; 2007.

[27] Saluja G, Iachan R, Scheidt PC, et al. Prevalence of and risk factors for depressive symptoms among young adolescents. Arch Pediatr Adolesc Med 2004;158:760-5.

[28] Wang J, Nansel TR, Iannotti RJ. Cyber and traditional bullying: Differential association with depression. J Adolesc Health 2011;48:415-7.

[29] Kaltiala-Heino R, Frojd S. Correlation between bullying and clinical depression in adolescent patients. Adolesc Health Med Ther 2011;2:37-44.

[30] Kaltiala-Heino R, Frojd S, Marttunen M. Involvement in bullying and depression in a 2-year follow-up in middle adolescence. Eur Child Adolesc Psychiatry 2010;19:45-55.

[31] Tennant C. Life events, stress and depression: A review of recent findings. Aust N Z J Psychiatry 2002;36:173-82.

[32] Mahatme S, Dhavale H, Patkar A. Study of correlation of intensity of symptoms with stressful life events in depressed patients. Indian J Psychiatry 1989;31:288-92.

[33] Olsson I, Nordstroem ML, Arinell H, et al. Adolescent depression and stressful life events. Nord J Psychiatry 1999;53:339-46.

[34] Tafet GE, Bernardini R. Psychoneuroendocrinological links between chronic stress and depression. Prog Neuropsychopharmacol Biol Psychiatry 2003; 27:893-903.

[35] McEwen BS. Protection and damage from acute and chronic stress: Allostasis and allostatic overload and relevance to the pathophysiology of psychiatric disorders. Ann N Y Acad Sci 2004;1032:1-7. 